\title{
Biyokimyasal Reaksiyon Sistemlerinin Modellenmesi için Deterministik ve Stokastik Yaklaşım
}

\author{
Büşranur OĞRAŞ ${ }^{1}$, Derya ALTINTAN ${ }^{2 *}$
}

*Sorumlu yazar: busranurogras@hotmail.com

${ }^{1}$ Selçuk Üniversitesi, Fen Fakültesi, Matematik Bölümü, KONYA

Orcid No: 0000-0003-3264-0718 / busranurogras@hotmail.com

2* Selçuk Üniversitesi, Fen Fakültesi, Matematik Bölümü, KONYA

Orcid No: 0000-0003-3497-7760 / altintan@selcuk.edu.tr

Öz: Biyokimyasal süreçler, birbirleriyle, farklı reaksiyon kanallarıyla etkileşime giren türleri içeren reaksiyon ağları olarak düşünülebilirler. Deterministik yaklaşım ve stokastik yaklaşım bu sistemlerin dinamiklerini modelleyen iki temel yaklaşımdır. Deterministik yaklaşım geleneksel olandır ve bu tip sistemleri modellemek için Reaksiyon Oran Denklemleri (ROD) adı verilen Adi Diferansiyel Denklemleri (ADD) kullanır. Bu yaklaşıma göre sistem dinamikleri sürekli ve deterministiktir. Diğer taraftan, stokastik yaklaşım sistem dinamiklerinin stokastik ve kesikli olduğunu düşünür. Bu yaklaşımda, sistem dinamiklerini modelleyen olasılık fonksiyonunun zamana göre türevi ünlü Temel Kimyasal Denklemini (TKD) sağlar. Stokastik Simülasyon Algoritmaları (SSAs), TKD’nin davranışlarını tam olarak yansıtan bilgisayar tabanlı algoritmalardır. SSA'nın doğrudan ve ilk reaksiyon metodu olmak üzere iki farklı versiyonu vardır. Bu çalışmada, deterministik ve stokastik yaklaşımın temellerini ve birbirleriyle olan ilişkilerini açıkladık. Farklı boyutlardaki sistemlerin doğrudan metot ve ROD algoritmalarını R programlama dili ile yazdık ve kodlarımız ile birlikte simülasyon sonuçlarımızı sunduk.

Anahtar Kelimeler: Deterministik yaklaşım, Stokastik yaklaşım, Reaksiyon oran denklemleri, Temel kimyasal denklemi, Stokastik simülasyon algoritmaları

\section{Deterministic and Stochastic Approach for Modelling Biochemical Reaction Systems}

\begin{abstract}
Biochemical processes can be thought as a reaction network containing species interacting with each other via different reaction channels. Deterministic approach, stochastic approach are two fundamental approaches modelling the dynamics of these systems. Deterministic approach is the traditional one and it uses Ordinary Differential Equations (ODEs), namely, Reaction Rate Equations (RREs) to model these kind of systems. According to this approach, the system dynamics are continuous and deterministic. On the other hand, stochastic approach assumes that the system dynamics are stochastic adn deterministic. In this approach, the time derivative of the probability function representing the dynamics of the system satisfies the celebrated Chemical Master Equation (CME). Stochastic Simulation Algorithms (SSAs) are computer based algorithms which generate exact realizations of the given CME. There are two versions of SSAs which are direct method and first reaction method. In this study, we explain the bases of deterministic approach, stochastic approach and their relations with each other. We have written SSA direct and RRE algorithms of systems in different sizes by using $R$ programming language and presented our simulation results together with our codes.
\end{abstract}

Keywords: Deterministic approach, Stochastic approach, Reaction rate equations, Chemical master equation, Stochastic simulation algorithms 


\section{Giriş}

Biyolojik, ekolojik ve kimyasal süreçleri farklı türlerin birbirleriyle etkileşime girdiği reaksiyon kanalları olarak düşünmek mümkündür. Dolayısıyla söz konusu süreçlerin dinamiklerinin anlaşılması için üretilen matematiksel modeller, farklı alanlardan birçok araştırmacının ilgisini çekmektedir (Gillespie, 1976; Laise ve ark., 2011; Macnamara ve ark., 2008; McAdams ve ark., 1997; Srivastava ve ark., 2002; Steijaert ve ark., 2010; Steuer, 2004; Ullah ve ark., 2006; Warmflash ve ark., 2008). Deterministik ve stokastik yaklaşım bu süreçlerin matematiksel modellenmesinde en yaygın olarak kullanılan yaklaşımlardır. Zaman içerisinde bu yaklaşımlara ek olarak difüzyon modelleri ile deterministik ve stokastik yaklaşımları harmanlayarak elde edilen melez modeller de geliştirilmiştir (Cao ve ark., 2005; Crudu ve ark., 2009; Salis ve ark., 2005).

Geleneksel yaklaşım olan deterministik yaklaşım, bu sistemleri modellerken konum vektörleri olarak reel değerli konsantrasyonları kullanır ve sistemin hareketlerinin deterministik olduğunu yani olasılık fonksiyonuna bağlı olmadığını düşünür (Murray, 2003; Wilkinson, 2006). Sistem dinamiklerini açıklamak içinse, konsantrasyonların zamana göre türevlerinin oluşturduğu bir adi diferansiyel denklem sistemi olan Reaksiyon Oran Denklemlerini (ROD) kullanılır. Elde edilen ROD denklemlerini çözümlerini kullanarak, sistemin dinamikleri ile ilgili öngörülerde bulunmak mümkündür (Jain, 1984). Bu yaklaşım birçok model için geçerli olabilir. Fakat incelenen sistemde yer alan bazı türlerin miktarları azsa ve stokastik dalgalanmalar sistemin davranışlarını çok etkiliyorsa bu durumda geleneksel yaklaşım olan deterministik yaklaşım yeterli olmayabilir (Cao ve ark., 2004; Gillespie, 2007).

Stokastik yaklaşım bu dezanatajları gidermek için deterministik yaklaşıma alternatif olarak üretilmiştir. Deterministik yaklaşımdan farklı olarak bu yaklaşım, konum vektörü olarak, türlerin doğal sayı değerli molekül sayılarını kullanır ve sistem hareketlerinin stokastik olduğunu yani sistem dinamiklerini açıklayan olasılık fonksiyonuna bağlı olduğunu düşünür (Gillespie, 1976; Gillespie, 1977-1992). Örneğin; Arkin ve ark. (1998) ve McAdams ve ark. (1997)'da gen ekspresyonlarının modellenmesinde stokastik yaklaşımın gerekli olduğu gösterilmiştir. Bu çalışmalara ek olarak, Jilbert ve ark. (1996)'da virüs enfeksiyolarının yayılmasında, Laise ve ark. (2011) ise kanser hücrelerinin gelişimlerinin modellenmesinde stokastik modellemenin ne kadar gerekli olduğu gösterilmiştir.

Stokastik yaklaşımda üzerinde çalışılan sistemin davranışlarını incelemek için, zaman ve konum vektörünü değişkenleri olarak kabul eden bir olasılık 
fonksiyonu tanımlanır. Elde edilen olasılık fonksiyonunun zamana bağlı türevi bir Kolmogorov ileri denklemi olan Temel Kimyasal Denklemini (TKD) verir.

TKD’nin analitik çözümlerini tek moleküllü bazı özel reaksiyon sistemleri için biliyor olmamıza rağmen (Jahnke ve ark., 2007), reaksiyon ağındaki türlerin ve reaksiyon kanallarının sayısı arttıkça analitik çözüm elde etmek güçleşir. Bu nedenle elde edilen TKD'nin davranışlarını tam olarak yansitan Stokastik Simülasyon Algoritmaları (SSA) önerilmiştir (Gillespie, 1976; Gillespie, 1977; Gillespie, 1992). Bu algoritmalara alternatif olarak zaman içerisinde sistemin dinamiklerini yaklaşık olarak elde eden algoritmalar ile sistemi deterministik ve stokastik parçalara ayırarak modelleyen bilgisayar tabanlı algoritmalar önerilmiştir (Cao ve ark., 2006; Cao ve ark., 2004; Gillespie, 2001; Jahnke ve ark., 2010; Purutçuoğlu ve ark., 2006; Rathinam ve ark., 2003). Gillespie'nin önerdiği SSA algoritmalarının iki farklı versiyonu vardır. Bunlar, doğrudan metot ve ilk reaksiyon metodudur. $\mathrm{Bu}$ metotların arasındaki temel fark oluşacak reaksiyonların zamanlarını ve indislerini bulmaktaki farklılıklarıdır (Gillespie, 1976; Gillespie, 1977; Gillespie, 1992).

Çalışmamızın amacı, deterministik ve stokastik yaklaşımların matematiksel temellerini ve bu iki yaklaşım arasındaki bağlantıyı açıklamaktır. Söz konusu yaklaşımlar, farklı boyutlardaki reaksiyon sistemlerine uygulanmış ve elde edilen simülasyon sonuçları ve $\mathrm{R}$ programlama dilinde yazılan algoritmaları ile birlikte sunulmuştur.

Çalışmamızın organizasyonu şu şekildedir: Bölüm II'de reaksiyon sistemlerinin nasıl oluşturulduğu açıklanmıştır. Bölüm III'de reaksiyon sistemlerinin modellenmesinde geleneksel olarak kullanılan deterministik yaklaşımın, Bölüm IV'de ise stokastik yaklaşımın temelleri anlatılmıştır. Bölüm III ve Bölüm IV'de Lotka-Volterra sisteminin dinamiklerini açıklayan denklemler ve simülasyon sonuçları anlatılanları somutlaştırmak için kullanılmıştır. Bölüm V'de deterministik ve stokastik modelleme arasındaki bağlantı açıklanmıştır. Bölüm VI'da deterministik ve stokastik yaklaşım farklı boyutlardaki sistemlere uygulanırken, bu bölümde kullanılan ve $\mathrm{R}$ programlama dilinde yazılan algoritmalar Ek'te sunulmuştur. Bölüm VII'de ise elde edilen sonuçlar yorumlanarak çalışmamız sonlandırılmıştır.

\section{Kimyasal Reaksiyonlar}

Kabul edelim ki $N \in \mathbb{N}$ tane türün, $\left\{S_{1}, S_{2}, \ldots, S_{N}\right\}$, homojen olarak karıştığı $M \in \mathbb{N}$ tane farklı reaksiyon kanalı yoluyla, $\left\{R_{1}, R_{2}, \ldots, R_{M}\right\}$, etkileşime girdiği bir reaksiyon sistemine sahibiz. $\mathrm{Bu}$ durumda, $j .(j=$ $1,2, \ldots, M)$ reaksiyon kanalını aşağıdaki 
şekilde yazabiliriz.

$$
R_{j}: a_{1 j} S_{1}+\cdots+a_{N j} S_{N} \stackrel{k_{j}}{\rightarrow} b_{1 j} S_{1}+\cdots+b_{N j} S_{N} .
$$

Burada $a_{i j} \in \mathbb{Z}^{+}, b_{i j} \in \mathbb{Z}^{+}$sirasiyla $i$. türün $j$. reaksiyon kanalıyla tüketilen, üretilen molekül sayısını göstermektedir; $k_{j} \geq 0$, ise $R_{j}$ 'nin reaksiyon sabiti olarak adlandırılır. $X_{i}(t), t \geq$ 0 anında $S_{i}$ türünün miktarını göstermek üzere sistemin $t \geq 0$ anındaki konum vektörü

$X(t)=\left(X_{1}(t), X_{2}(t), \ldots, X_{N}(t)\right)^{T}$ şeklindedir.

$\mathrm{Bu}$ durumda $t \geq 0$ anında $R_{j}$ reaksiyonu bir kez gerçekleşirse, sistemin konumu $X(t)$ 'den $X(t)+\eta_{j} \quad$ 'ye siçrar ki burada $\eta_{j}=$ $\left(\eta_{i j}\right)_{i=1}^{N}, \quad \eta_{i j}=b_{i j}-a_{i j}, j . \quad$ reaksiyonun net değişim vektörü olarak adlandırılır. Reaksiyonlar, reaksiyona giren türlerin sayısına göre tek moleküllü (monomolecular), çift moleküllü (bimolecular) ve üç moleküllü (trimolecular) reaksiyonlar olarak adlandırılırlar (Jahnke ve ark., 2007).

\section{Deterministik Yaklașim}

Reaksiyon sistemlerini matematiksel olarak modellemek için kullanılan en yaygın yaklaşım deterministik yaklaşımdır (Wilkinson, 2006). Bu yaklaşımda sistemin konum vektörünün bileşenleri türlerin konsantrasyonlarıdır. $\quad S_{i}$ türünün $t \geq 0$ anındaki konsantrasyonu $\left[X_{i}(t)\right]$ olmak üzere $S_{i}$ 'nin molekül sayısı ile konsantrasyonu arasinda $X_{i}(t)=\left[X_{i}(t)\right] N_{A} V$ şeklinde bir bağıntı mevcuttur. Burada,
$N_{A} \approx 6.10^{23} \quad$ Avogadro sabiti, $\quad V$ ise reaksiyonun gerçekleștiği bölgenin hacmidir (Higham, 2008; Wilkinson, 2006). Bu yaklaşım, sistem dinamiklerini, türlerin konsantrasyonlarının zamana bağlı türevlerinin oluşturduğu bir Adi Diferansiyel Denklem sistemi olan Reaksiyon Oran Denklemleri (ROD) ile açıklar. Söz konusu denklemler kitle eylem yasasına dayanırlar (Higham, 2008; Klipp ve ark., 2009; Roberts, 2013; Murray, 2003). ROD denklemini oluşturabilmek için her reaksiyonun aşağıda verilen değişim fonksiyonu

$$
r_{j}(t)=k_{j} \prod_{i=1}^{N}\left[X_{i}(t)\right]^{a_{i j}},
$$

bulunmalidır (Crudu ve ark., 2009). Bu oran değişim fonksiyonları kullanılarak $M$ reaksiyon kanalından oluşan bir sistemde $S_{i}$ türünün konsantrasyonunun zamana bağlı türevini,

$$
\frac{d}{d t}\left[X_{i}(t)\right]=\sum_{j=1}^{M} \eta_{i j} r_{j}(t)
$$

şeklinde verir.

Söylediklerimizi daha anlaşılır kılmak için aşağıdaki Lotka- Volterra sistemini düşünelim.

$$
\begin{gathered}
R_{1}: S_{1} \stackrel{k_{1}}{\rightarrow} 2 S_{1} \\
R_{2}: S_{1}+S_{2} \stackrel{k_{2}}{\rightarrow} 2 S_{2} \\
R_{3}: S_{1} \stackrel{k_{3}}{\rightarrow} \emptyset \\
R_{4}: S_{2} \stackrel{k_{4}}{\rightarrow} \emptyset
\end{gathered}
$$

Populasyon sistemlerinde, $\operatorname{Av}\left(S_{1}\right)-\operatorname{Avc1}\left(S_{2}\right)$ modeli olarak da bilinen bu sistemde, $R_{1}$ reaksiyonu avların doğmasını, $R_{2}$ reaksiyonu avcıların avları yemesini, $R_{3}$ ve $R_{4}$ reaksiyonları ise sirasıyla av ve avcıların 
ölmesini modellemektedir. $\mathrm{Bu}$ durumda sistemin konum vektörü

$$
[X(t)]=\left(\left[X_{1}(t)\right],\left[X_{2}(t)\right]\right)^{T}
$$

ve reaksiyon sisteminin net değişim vektörleri

$$
\begin{aligned}
& \eta_{1}=(1,0)^{T}, \eta_{2}=(-1,1)^{T}, \\
& \eta_{3}=(-1,0)^{T}, \eta_{4=}(0,-1)^{T}
\end{aligned}
$$

şeklindedir. Dolayısıyla, $\quad k_{1}, k_{2}, k_{3}, k_{4}$, reaksiyon sabitleri olmak üzere

$$
\begin{array}{ll}
r_{1}(t)=k_{1}\left[X_{1}(t)\right], & r_{2}(t)=k_{2}\left[X_{1}(t)\right]\left[X_{2}(t)\right] \\
r_{3}(t)=k_{3}\left[X_{1}(t)\right], & r_{4}(t)=k_{4}\left[X_{2}(t)\right]
\end{array}
$$

şeklindedir. $\mathrm{Bu}$ ise bize aşağıdaki ROD sistemini verir.

$$
\begin{aligned}
& \frac{d\left[X_{1}(t)\right]}{d t}=r_{1}(t)-r_{2}(t)-r_{3}(t) \\
& =k_{1}\left[X_{1}(t)\right]-k_{2}\left[X_{1}(t)\right]\left[X_{2}(t)-k_{3}\left[X_{1}(t)\right]\right. \\
& \frac{d\left[X_{2}(t)\right]}{d t}=r_{2}(t)-r_{4}(t) \\
& =k_{2}\left[X_{1}(t)\right]\left[X_{2}(t)\right]-k_{4}\left[X_{2}(t)\right]
\end{aligned}
$$

Elde ettiğimiz sistem bir diferansiyel denklem sistemi olduğu için çözümünde Euler, Runge Kutta v.b. metotlar kullanılabilir (Jain, 1984).

Şekil 1'de Ekte yer alan Algoritma 3 kullanılarak elde edilen, deterministik modelin simülasyonları görülebilir.

Simülasyonumuzda başlangıç değeri $X(0)=$ $(100,90)^{T}$, reaksiyon oran sabitleri ise $k_{1}=$ $1, k_{2}=0.01, k_{3}=0.01, k_{4}=1, t \in$ $[0,30]$ olarak alınmıştır.

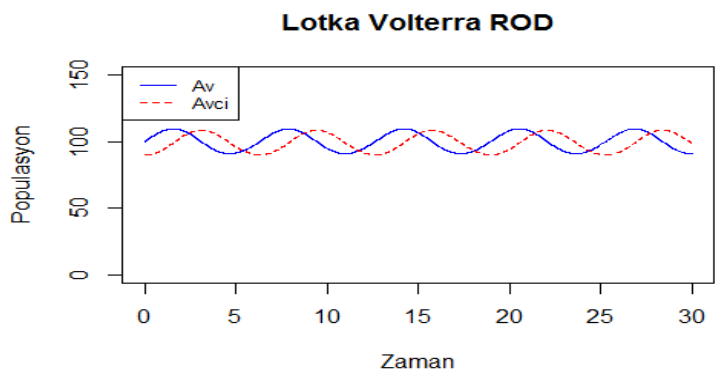

Şekil 1. Lotka- Volterra (Av-Avc1) modelinin deterministik yaklaşım ile elde edilen reaksiyon oran denkleminin (3) simülasyon sonuçları.
Lotka-Volterra modeli av veya avcının azalıp çoğaldığg fakat tamamen yok olmadığg dalgasal bir modeli temsil eder. Bunun nedeni, avın azaldığı ve hatta tükenmesi durumunda avcının da tükenmeye doğru gitmesidir. Dolayısıyla Şekil 1'de bu durum dalgasal olarak görülmektedir. Başlangıçta avcı grubu az iken av grubu hızla artmaktadır. Avcı grubu birden fazla av1 tüketebileceğinden avda azalma görülmektedir. Reaksiyon sisteminden de ilk reaksiyonda Avı temsil eden $\left(S_{1}\right)$ türü ilk reaksiyonda artmakta iken $R_{2}$ reaksiyonunda azalmaktadır. Aynı şekilde Avciyı temsil eden $\left(S_{2}\right)$ türü de $R_{2}$ reaksiyonunda artmakta iken $R_{4}$ reaksiyonunda azamaktadır.

Deterministik yaklaşım birçok problem için uygun olmasına rağmen geçerliliğini bozan durumlar vardır (Gillespie, 2007). Bu nedenle deterministik yaklaşıma alternatif olarak stokastik yaklaşım önerilmiştir. Bir sonraki bölümde deterministik yaklaşıma alternatif olarak önerilen stokastik yaklaşım üzerine çalışılacaktır.

\section{Stokastik Yaklaşim}

Deterministik yaklaşımdan farklı olarak stokastik yaklaşım, sistem dinamiklerinin stokastik ve kesikli olduğunu düşünür (Gillespie, 1992; Gillespie, 2007; Jahnke, 2010). Bu yaklaşıma göre her $R_{j},(j=$ $1,2, \ldots M), \quad$ reaksiyonunun davranışını açıklayan iki temel kavram vardır. Bunlardan birisi bir önceki bölümde anlatılan $\eta_{j}$ net 
değişim vektörü diğeri ise $\alpha_{j}: \mathbb{Z}_{+}^{N} \rightarrow \mathbb{R}_{\geq 0}$ eğilim fonksiyonudur. Bu fonksiyon $\alpha_{j}(x)=$ $c_{j} h_{j}(x)$ olarak tanımlanır. Burada, $c_{j}$ stokastik reaksiyon sabitini, $h_{j}(x)$ ise $R_{j}$ reaksiyonunda, harcanan türlerin farklı kombinasyonlarını göstermektedir (Kampen, 1981; Gillespie, 1976; Gillespie, 1977; Gillespie, 1992). Stokastik reaksiyon sabiti $c_{j}$ ile deterministik reaksiyon sabiti $k_{j}$ oldukça yakından ilişkilidir (Wilkinson, 2006). Elimizdeki çalı̧smada $V=1, k_{j}=c_{j}$ olarak alınmıştır.

Stokastik yaklaşımın temel dayanağına göre $[t, t+d t)$ zaman aralığında, $x$ konumunda $R_{j}$ reaksiyonun gerçekleşme olasılığ $\alpha_{j}(x) d t$ 'dir. Stokastik yaklaşım, sistemin başlangıç konumu $X(0)=x_{0}$ iken $t$ anındaki konumunun $\quad X(t)=x \quad$ olması olasıllı̆ını gösteren

$$
p(x, t)=\mathbb{P}\left(X(t)=x \mid X(0)=x_{0}\right)
$$

olasılık fonksiyonunu elde etmeyi amaçlar. $M$ tane reaksiyon kanalından oluşan bir reaksiyon sisteminde bu olasıllk fonksiyonu bir Kolmogorov ileri denklemi olan ve aşağıda verilen Temel Kimyasal Denklemini (TKD)

$$
\frac{\partial p(x, t)}{\partial t}=\sum_{\mu=1}^{M}\left[\alpha_{\mu}\left(x-\eta_{\mu}\right) p\left(x-\eta_{\mu}, t\right)-\alpha_{\mu}(x) p(x, t)\right]
$$

sağlar. Sistemin başlangıç koşulu ise

$$
p\left(x, t_{0}\right)= \begin{cases}1, & \text { eğer } x=x_{0} \\ 0, & \text { eğer } x \neq x_{0}\end{cases}
$$

şeklindedir. Temel Kimyasal Denklemi aynı zamanda bir diferansiyel denklem olduğundan çözümü için Euler, Runge Kutta gibi çözüm metotlar1 kullanılabilir (Jain, 1984). Bu durumda (2)'de verilen Lotka Volterra sistemine dönersek $R_{j}, \quad(j=1,2,3,4)$, reaksiyonlarının eğilim fonksiyonları aşağıdaki şekilde elde edilir.

$\alpha_{1}(x)=c_{1} x_{1}, \alpha_{2}(x)=c_{2} x_{1} x_{2}, \alpha_{3}(x)=c_{3} x_{1}, \alpha_{4}(x)=c_{4} x_{2}$.

$\mathrm{Bu}$ durumda (2) reaksiyon sistemine karşıllı gelen TKD

$$
\begin{aligned}
& \quad \frac{\partial p(x, t)}{\partial t}=c_{1}\left(x_{1}-1\right) p\left(x_{1}-1, x_{2}, t\right)-c_{1} x_{1} p\left(x_{1}, x_{2}, t\right) \\
& +c_{2}\left(x_{1}+1\right)\left(x_{2}-1\right) p\left(x_{1}+1, x_{2}-1, t\right)-c_{2} x_{1} x_{2} p\left(x_{1}, x_{2}, t\right) \\
& +c_{3}\left(x_{1}+1\right) p\left(x_{1}+1, x_{2}, t\right)-c_{3} x_{1} p\left(x_{1}, x_{2}, t\right) \\
& +c_{4}\left(x_{2}+1\right) p\left(x_{1}, x_{2}+1, t\right)-c_{4} x_{2} p\left(x_{1}, x_{2}, t\right)
\end{aligned}
$$

şeklindedir. Bazı özel reaksiyon sistemleri için TKD'nin analitik çözümü elde edilebilir olsa da (Jahnke ve ark., 2007) reaksiyon sistemlerinde yer alan türlerin ve reaksiyonların sayıları arttıkça analitik çözümün elde edilmesi oldukça zorlaşır. Bu nedenle, elde edilen TKD'nin davranışlarını tam olarak yansitan Stokastik Simülasyon algoritmaları Gillespie tarafından önerilmiştir (Gillespie, 2007). Zamanla SSA'nın farklı versiyonları (Gibson ve ark., 2000; Gillespie, 2001; Cao ve ark., 2006), SSA ve/veya versiyonların kullanan melez algoritmalar (Crudu ve ark., 2009; Jahnke ve ark., 2010; Ganguly ve ark., 2015; Altıntan ve ark., 2020) geliştirilse de SSA algoritmaları hala referans olarak kullanılan algoritmadır.

SSA algoritmaları reaksiyon olasılık fonksiyonuna dayanır. Bu fonksiyon gelecek reaksiyonun ne kadar süreceğini gösteren $\tau$ ve gelecek reaksiyonun $j$ hangi reaksiyon 
olduğunu tanımlayan rastgele değişkenlerin oluşturduğu bir birleşik olasılık fonksiyonudur (joint probability function). Bu fonksiyon $M$ tane reaksiyondan oluşan bir reaksiyon ağı için

$$
P(\tau, j)=\alpha_{j}(x) e^{\alpha_{0}(x)}, \alpha_{0}(x)=\sum_{j=1}^{M} \alpha_{j}(x)
$$

şeklindedir. SSA’nın iki farklı versiyonu olan doğrudan metot ile ilk reaksiyon metodu arasındaki temel fark $(\tau, j)$ ikilisinin elde edilme şeklidir (Gillespie, 1976; Gillespie, 1992 ).

Bir sonraki bölümümüzde deterministik yaklaşım ile stokastik yaklaşım arasındaki bağlantıyı inceleyeceğiz.

\section{Deterministik ve Stokastik}

\section{Yaklaşım Arasındaki Bağlantı}

Deterministik yaklaşım ile stokastik yaklaşım her ne kadar birbirlerinden farklı olarak görünseler de birbirlerinden tamamen bağımsız değildirler. Bunun için, stokastik yaklaşım da $X(t)$ rastgele değişkeni gösterilen sistemin konum vektörünün beklenen değeri $E(X(t))^{\prime}$ nin zamana göre türevine bakacağız (Wilkinson, 2006). $\mathrm{Bu}$ beklenen değer aşağıdaki şekilde tanımlanır. $E(X(t))=\sum_{x \in \kappa} x p(X(t)=x)$

Burada $\kappa \quad$ sistemin sayılabilir konum uzayıdır. $\mathrm{Bu}$ durumda beklenen değerin zamana göre türevi

$\frac{\partial}{\partial t} E(X(t))=\frac{\partial}{\partial t} \sum_{x \in \kappa} x p(x, t)=\sum_{x \in \kappa} x \frac{\partial}{\partial t} p(x, t)$ $=\sum_{x \in K} x \sum_{j=1}^{M}\left[\alpha_{j}\left(x-\eta_{j}\right) p\left(x-\eta_{j}, t\right)-\alpha_{j}(x) p(x, t)\right]$

$=\sum_{j=1}^{M}\left[\sum_{x \in \kappa} x \alpha_{j}\left(x-\eta_{j}\right) p\left(x-\eta_{j}, t\right)-\sum_{x \in \kappa} x \alpha_{j}(x) p(x, t)\right]$

$=\sum_{j=1}^{M}\left[\sum_{x \in \kappa}\left(x+\eta_{j}\right) \alpha_{j}(x) p(x, t)-\sum_{x \in \kappa} x \alpha_{j}(x) p(x, t)\right]$

$=\sum_{j=1}^{M}\left[E\left(\left(X(t)+\eta_{j}\right) \alpha_{j}(X(t))\right)-E\left(X(t) \alpha_{j}(X(t))\right)\right]$

$=\sum_{j=1}^{M} E\left(\eta_{j} \alpha_{j}(X(t))\right)=\sum_{j=1}^{M} \eta_{j} E\left(\alpha_{j}(X(t))\right)$

şeklindedir. Eğer, $j$. fonksiyon lineer ise $E\left(\alpha_{j}(X(t))\right)=\alpha_{j}(E(X(t))) \quad$ eşitliği elde edilir. Yani, $\frac{\partial}{\partial t} E(X(t))=\sum_{j=1}^{M} \eta_{j} \alpha_{j}(E(X(t))) \quad$ şeklini alır. Dikkat edilirse bu denklem (1)'de verilen ROD ile aynıdır.

Şimdiye kadar anlattıklarımızı Lotka-Volterra (Av-Avc1) modeli ile ayrıntılı inceleyeceğiz. Biz çalışmamızda doğrudan metodu kullanacağız. (2)'de verilen Lotka-Volterra sisteminin, Ekte yer alan Algoritma 1 kullanılarak Doğrudan Metot ile elde edilen simülasyonları Şekil 2'de, deterministik yaklaşım ile stokastik yaklaşımın karşılaştırılması ise Şekil 3 ve Şekil 4 de görülebilir. Şekil 2 ve Şekil 3'te de Şekil 1'de olduğu gibi başlangıç değeri $X(0)=$ $(100,90)^{T}$, reaksiyon oran sabitleri ve zaman aralığ1 ise $k_{1}=1, k_{2}=0.01, k_{3}=0.01, k_{4}=1$, $t \in[0,30]$ olarak alınmıştır 


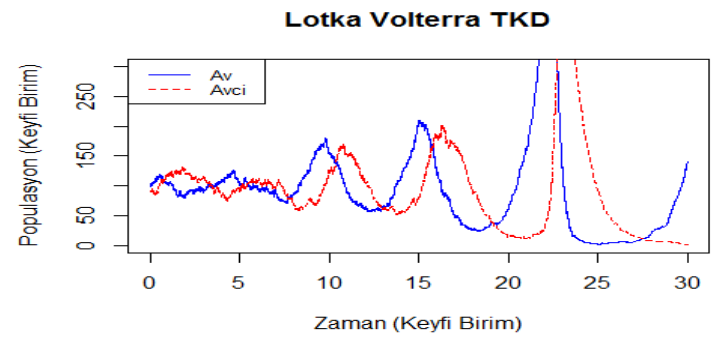

Şekil 2. Lotka- Volterra (Av-Avcı) modelinin stokastik yaklaşım ile elde edilen temel kimyasal denkleminin (4), doğrudan metot ile elde edilen simülasyon.

Deterministik yaklaşımda Şekil 1'de çizgiler düz iken stokastik yaklaşımda Şekil 2'de çizgilerin kesikli olduğu görülür. Stokastik yaklaşımda konum vektörü kesikli olduğu için grafiği de kesikli olmaktadır. Diğer taraftan SSA algoritmalarının doğası gereği her bir simülasyonda yeni rastgele değişkenler üretileceği için her bir simülasyonda farklı fakat birbirine yakın grafikler elde edilecektir. $\mathrm{Bu}$ da stokastik etkiyi ortaya koymaktadir.

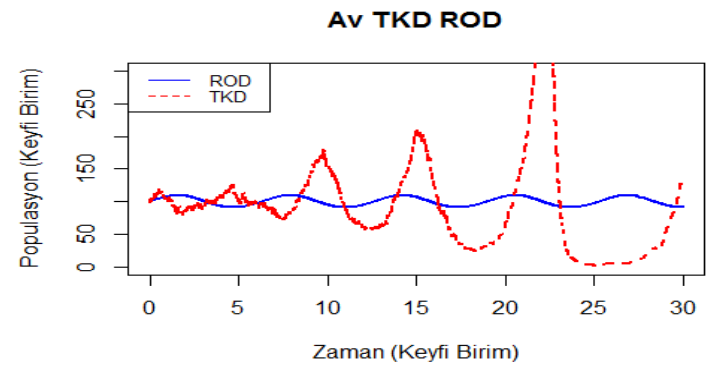

Şekil 3. Lotka- Volterra (Av-Avc1) modelinin deterministik modelde elde edilen ROD denklemi (3) ile stokastik yaklaşım ile elde edilen temel kimyasal denkleminin (4), doğrudan metot ile elde edilen simülasyonunun Av için karşılaştırılması

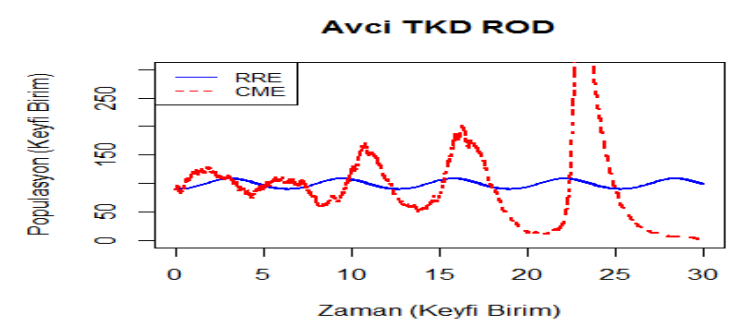

Şekil 4. Lotka- Volterra (Av-Avcı) modelinin deterministik modelde elde edilen ROD denklemi (3) ile stokastik yaklaşım ile elde edilen temel kimyasal denkleminin (4), doğrudan metot ile elde edilen simülasyonunun Av için karşılaştırılması
Elde ettiğimiz simülasyonlar doğrudan metodun sadece bir kez çalıştırılması ile elde edilen simülasyonlardır. $\mathrm{Bu}$ grafiklerde görülen sıçramalar stokastik simülasyon algoritmasının bir kez çalıştırılması ile ilgilidir. $\mathrm{Bu}$ simülasyonlar birden çok çalıştırıldığında ve her $t \geq 0$ anında elde edilen $X(t)$ konum vektörlerinin ortalamaları alındığında Şekil 1 ve Şekil 2'nin birbirine çok yakın olacağı görülecektir. Bunun teorik açıklaması beklenen değerlerle aşağıdaki şekilde verilmiştir.

$\frac{\partial}{\partial t} E\left[X_{1}(t)\right]=c_{1} E\left[X_{1}(t)\right]-c_{2} E\left[X_{1}(t) X_{2}(t)\right]-c_{3} E\left[X_{1}(t)\right]$
$\frac{\partial}{\partial t} E\left[X_{2}(t)\right]=c_{2} E\left[X_{1}(t) X_{2}(t)\right]-c_{4} E\left[X_{2}(t)\right]$

Burada, lineer olmayan bir $g$ fonksiyonu ve $Z(t) \quad$ rastgele değişkeni için $E[f(Z(t))] \neq f(E[Z(t)]) \quad$ olduğu unutulmamalıdır. Dolayısıyla, $\quad R_{2}$ reaksiyonunda eğilim fonksiyonu lineer olmadığından (6) denkleminin

denklemindeki ROD’e eşit olmadığı görülür.

\section{UYGULAMALAR}

Çalışmamızın bu bölümünde, klasik bir model olan doğum ölüm süreçleri ile Glikoz modelinin ROD, ve TKD'lerini elde edilecektir. Bunlara ek olarak elde edilen denklemlere ait simülasyon sonuçları sunulacaktır. Tüm uygulamalar Rstıdio, version 1.3.1093, programlama dilinde yazılmış olup tüm algoritmalar Ekte görülebilir. 


\section{Doğum Ölüm Reaksiyonları}

Doğum-ölüm modeli, tek tür içeren bir reaksiyon modelidir. Okuyucunun sistemi daha iyi anlaması açısından bu bölüme konulmas1 uygun görülmüştür. Doğum-ölüm modelinin reaksiyon sistemi, karşıllı gelen net değişim vektörleri ve eğilim fonksiyonları aşağıdaki şekilde verilir

$$
\begin{aligned}
& R_{1}: \stackrel{k_{1}}{\rightarrow} S, \quad \eta_{1}=1, \alpha_{1}=c_{1}, \\
& R_{2}: S \stackrel{k_{2}}{\rightarrow} \emptyset, \quad \eta_{2}=-1, \alpha_{1}=c_{2} x .
\end{aligned}
$$

$\mathrm{Bu}$ reaksiyon sisteminde ilk reaksiyon doğum, ikinci reaksiyon ise doğum ölüm reaksiyonu olarak adlandırılır. Bu sisteme karşılık gelen ROD aşağıdaki şekilde iken

$\frac{d}{d t}[S(t)]=k_{1}-k_{2}[S(t)]$

TKD aşağıdaki şekildedir.

$\frac{\partial p(x, t)}{\partial t}=c_{1} p(x-1, t)-c_{1} p(x, t)+c_{2}(x+1) p(x+1, t)-c_{2} x p(x, t)$

Sistemin konum vektörü $t \geq 0$ anındaki konum vektörü, $X(t)=S(t)$ ile belirlenirken $X(0)=5$, deterministik ve stokastik reaksiyon oranları birbirine eşit ve $k_{1}=10, k_{2}=1$ şeklinde alınırsa $t \in[0,20]$ aralığında , sirasiyla Ekte yer alan Algoritma 1, Algoritma 2 ile elde edilen stokastik, deterministik yaklaşımdan elde edilen simülasyon sonuçları aşağıdaki şekilde görülebilir.

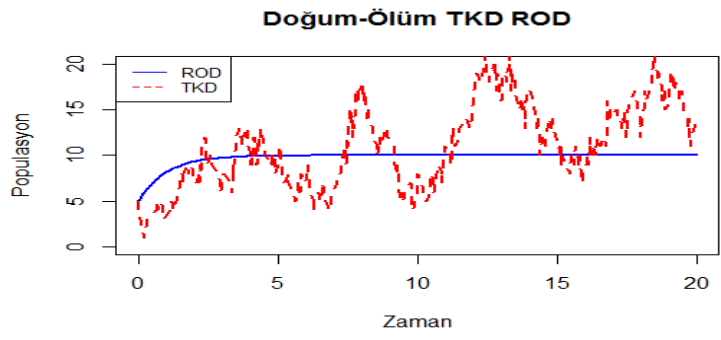

Şekil 5. Doğum ölüm reaksiyon sisteminin deterministik ve stokastik yaklaşım ile elde edilen simülasyon sonuçları.

Şekilde $X(0)=5$ başlangıç konumundayken zamanla arttığı ve daha sonra sabit ilerlediği görülmektedir. $\mathrm{Bu}$ durum sistemin dengede olduğunu ifade eder. Doğum-ölüm modeli için elde edilen beklenen değer,

$\frac{\partial}{\partial t} E[X(t)]=c_{1}-c_{2} E[X(t)]$

şeklindedir. Bu eşitliğin (7) denklemi ile aynı olduğu görülür. Doğum-ölüm modelinin eğilim fonksiyonları lineer olduğundan (7) ve (9) eşitlikleri birebir aynıdır.

\section{Glikoz Modeli}

Glikoz modeli, altı türün etkileşime girmesi ile oluşan bir reaksiyon sistemidir (Klipp ve ark., 2009). Aşağıda glikoz modelinin reaksiyon sistemi verilmiştir:

$R_{1}: * \stackrel{k_{1}}{\longrightarrow}$ Glikoz

$R_{2}:$ Glikoz $+A T P \stackrel{k_{2}}{\longrightarrow}$ Glikoz $6 P+A D P$

$R_{3}:$ Glikoz $6 P \stackrel{k_{3}}{\longrightarrow}$ Fruc $6 P$

$R_{4}: F_{r u c 6 P} \stackrel{k_{4}}{\longrightarrow}$ Glikoz6P

$R_{5}: F r u c 6 P+A T P \longrightarrow \stackrel{k_{s}}{\longrightarrow} F r u c 1.6 P_{2}+A D P$

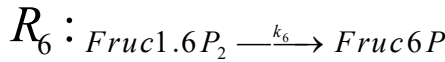

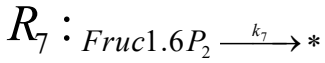

$R_{8}: A D P \stackrel{k_{8}}{\longrightarrow} A T P$ 
Uygulamalarınızda,

reaksiyon sisteminin $t \geq 0$ anındaki konum vektörï $X(t)=\left(\text { Glikoz }, \text { Glikoz6P }, \text { Fruc6 } P, \text { Fruc1 } 6 P_{2}, A T P, A D P\right)^{T}$

olarak belirlenmiş ve konum vektörünün başlangıç değeri $X(0)=(8,2,1,3,5,5)^{T}$, reaksiyon oran sabitleri ise

$$
\begin{aligned}
& k_{1}=0.25, k_{2}=0.03, k_{3}=0.1, k_{4}=1, \\
& k_{5}=1, k_{6}=1, k_{7}=1, k_{8}=2.5
\end{aligned}
$$

olarak belirlenmiştir. Daha önce belirttiğimiz üzere deterministik ve stokastik reaksiyon oran sabitleri birbirlerine eşit olarak alınmıştır. Glikoz modelinin ROD aşağıdaki şekilde ifade edilir.

$\frac{d}{d t}[$ Glikoz $]=k_{1}-k_{2}[$ Glikoz $][$ ATP $]$

$\frac{d}{d t}[$ Glikoz6P $]=k_{2}[$ Glikoz $][A T P]-k_{3}[$ Glikoz6P $]+k_{4}[$ Fruc $6 P]$

$\frac{d}{d t}[$ Fruc $6 P]=k_{3}[$ Glikoz $6 P]-k_{4}[$ Fruc $6 P]-k_{5}[$ Fruc $6 P][$ ATP $]+k_{6}[$ Fruc1.6P 2$]$

$\frac{d}{d t}[$ Frucl.6P 2$]=k_{5}[$ Fruc6P $][$ ATP $]-k_{6}[$ Fruc1.6P 2$]-k_{7}[$ Fruc1.6P 2$]$

$\frac{d}{d t}[A T P]=-k_{2}[$ Glikoz $][A T P]-k_{5}[$ Fruc $6 P][A T P]+k_{8}[A D P]$

$\frac{d}{d t}[A D P]=k_{2}[$ Glikoz $][A T P]+k_{5}[$ Fruc $6 P][A T P]-k_{8}[A D P]$

ROD’nin verilen başlangıç değeri ve reaksiyon oran sabitleri kullanılarak $t \in$ $[0,30]$ aralığında Ekte yer alan Algoritma 4 yoluyla elde edilen simülasyon sonuçları aşağıdaki şekilde görülebilir.

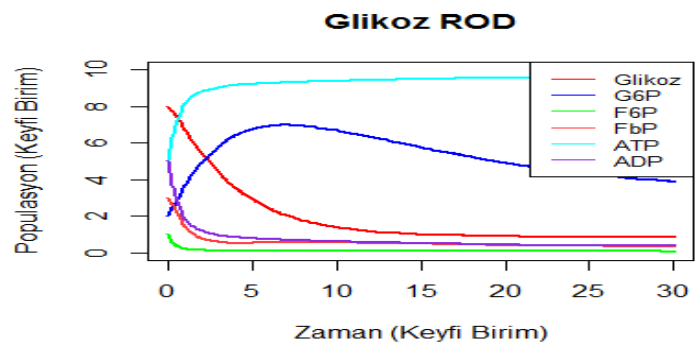

Sekil 6. Glikoz modelinin deterministik yaklaşım ile elde edilen reaksiyon oran denkleminin (6), Algoritma 4 ile elde edilen simülasyon sonuçları.

Glikoz modelinde, Glikoz molekülü $R_{1}$ reaksiyonunda üretilmekte iken $R_{2}$ reaksiyonunda reaksiyonunda harcandiğ 1 görülmektedir. Dolayısıyla bu molekülün zamanla azalması beklenmektedir. Aynı şekilde $\quad R_{2}, R_{5} \quad$ ve $\quad R_{8} \quad$ reaksiyonlarında görüldüğü üzere ATP ve ADP molekülü birbirine dönüşmektedir. $\mathrm{Bu}$ moleküllerin diferansiyel denklemleri incelendiğinde, toplamlarının sıfıra eşit olması da bu durumu belirtmektedir. Fruc6P ve Fruc1.6 $P_{2}$ molekülleri de önce ürün olarak oluşmakta iken daha sonra reaksiyona girerek azalmaktadır. Belirtilen durumların hepsini Şekil 6 ve Şekil 7'de görmek mümkündür.

Glikoz modelinin stokastik yaklaşımda kullanılacak net değişim vektörleri ve eğilim fonksiyonları aşağıdaki tabloda görülebilir.

Tablo 1. Glikoz modelinin eğilim fonksiyonları ve net

\begin{tabular}{|c|c|c|}
\hline Reaksiyon & $\begin{array}{c}\text { Eğilim } \\
\text { fonksiyonları }\end{array}$ & $\begin{array}{c}\text { Net değişim } \\
\text { Vektörleri }\end{array}$ \\
\hline$*$ — $\longrightarrow$ G Glikoz & $\alpha_{1}(x)=c_{1}$ & $\eta_{h}=(1,0,0,0,0,0)^{T}$ \\
\hline Glikoz $+A T P \stackrel{c_{2}}{\longrightarrow}$ Glikoz $6 P+A D P$ & $\alpha_{2}(x)=c_{2} x_{1} x_{5}$ & $\eta_{2}=(-1,1,0,0,-1,1)^{T}$ \\
\hline Glikoz $6 P \longrightarrow \stackrel{c_{3}}{\longrightarrow}$ Fruc $6 P$ & $\alpha_{3}(x)=c_{3} x_{2}$ & $\eta_{3}=(0,-1,1,0,0,0)^{T}$ \\
\hline Fruc6P $\longrightarrow \stackrel{c_{S}}{\longrightarrow}$ G likoz $6 P$ & $\alpha_{4}(x)=c_{4} x_{3}$ & $\eta_{4}=(0,1,-1,0,0,0)^{T}$ \\
\hline$F r u c 6 P+A T P \longrightarrow a^{a} \longrightarrow$ Fruc $1.6 P_{2}+A D P$ & $\alpha_{5}(x)=c_{5} x_{3} x_{5}$ & $\eta_{\mathrm{b}}=(0,0,-1,1,-1,1)^{T}$ \\
\hline Fnucl. $6 P_{2} \stackrel{c_{6}}{\longrightarrow}$ Fnuc6 $P$ & $\alpha_{6}(x)=c_{6} x_{4}$ & $\eta_{6}=(0,0,1,-1,0,0)^{T}$ \\
\hline Frucl.6P $P_{2} \stackrel{c_{7}}{\longrightarrow} *$ & $\alpha_{7}(x)=c_{7} x_{4}$ & $\eta_{h}=(0,0,0,-1,0,0)^{T}$ \\
\hline$A D P \stackrel{c_{\mathrm{s}}}{\longrightarrow} A T P$ & $\alpha_{8}(x)=c_{8} x_{6}$ & $\eta_{8}=(0,0,0,0,1,-1)^{T}$ \\
\hline
\end{tabular}
değişim vektörleri.

$\mathrm{Bu}$ durumda Glikoz reaksiyon sistemi için aşağıdaki TKD elde edilir.

$\frac{\partial}{\partial t} p(x, t)=c_{1} p\left(x_{1}-1, x_{2}, x_{3}, x_{4}, x_{5}, x_{6}, t\right)-c_{1} p\left(x_{1}, x_{2}, x_{3}, x_{4}, x_{5}, x_{6}, t\right)$ $+c_{2}\left(x_{1}+1\right)\left(x_{5}+1\right) p\left(x_{1}+1, x_{2}, x_{3}, x_{4}, x_{5}+1, x_{6}, t\right)-c_{2} x_{1} x_{5} p\left(x_{1}, x_{2}, x_{3}, x_{4}, x_{5}, x_{6}, t\right)$ 
$+c_{3}\left(x_{2}+1\right) p\left(x_{1}, x_{2}+1, x_{3}, x_{4}, x_{5}, x_{6}, t\right)-c_{2} x_{2} p\left(x_{1}, x_{2}, x_{3}, x_{4}, x_{5}, x_{6}, t\right)$

$+c_{4}\left(x_{3}+1\right) p\left(x_{1}, x_{2}, x_{3}+1, x_{4}, x_{5}, x_{6}, t\right)-c_{4} x_{3} p\left(x_{1}, x_{2}, x_{3}, x_{4}, x_{5}, x_{6}, t\right)$

$+c_{5}\left(x_{3}+1\right)\left(x_{5}+1\right) p\left(x_{1}, x_{2}, x_{3}+1, x_{4}, x_{5}+1, x_{6}, t\right)-c_{5} x_{3} x_{5} p\left(x_{1}, x_{2}, x_{3}, x_{4}, x_{5}, x_{6}, t\right)$

$+c_{6}\left(x_{4}+1\right) p\left(x_{1}, x_{2}, x_{3}, x_{4}+1, x_{5}, x_{6}, t\right)-c_{6} x_{4} p\left(x_{1}, x_{2}, x_{3}, x_{4}, x_{5}, x_{6}, t\right)$

$+c_{7}\left(x_{4}+1\right) p\left(x_{1}, x_{2}, x_{3}, x_{4}+1, x_{5}, x_{6}, t\right)-c_{7} x_{4} p\left(x_{1}, x_{2}, x_{3}, x_{4}, x_{5}, x_{6}, t\right)$

$+c_{8}\left(x_{6}+1\right) p\left(x_{1}, x_{2}, x_{3}, x_{4}, x_{5}, x_{6}+1, t\right)-c_{4} x_{6} p\left(x_{1}, x_{2}, x_{3}, x_{4}, x_{5}, x_{6}, t\right)$

(11)

Verilen başlangıç değerleri ve reaksiyon oran sabitlerinin Ekte yer alan Algoritma 1'de kullanılması ile TKD'nin tam simülasyonları aşağıda elde edilmiştir.

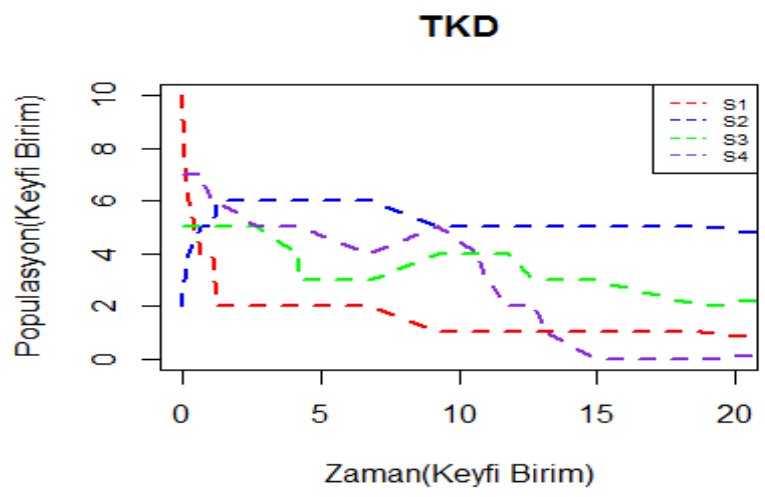

Şekil 7. Glikoz modelinin stokastik yaklaşım ile elde edilen reaksiyon oran denkleminin (7), Algoritma 1 ile elde edilen simülasyon sonuçları.

\section{SONUÇ}

Çalışmamızda reaksiyon sistemlerinin modellenmesinde kullanılan temel yaklaşımlar olan deterministik ve stokastik yaklaşımların temelleri anlatılmıştır. Ayrıca, bu yaklaşımların birbiriyle olan ilişkileri açıklanmıştır.

Söz konusu yaklaşımlar farklı boyutlardaki sistemlere uygulanmış ve simülasyon sonuçları sunulmuştur. Çalışmamızın orjinal parçası olarak $\mathrm{R}$ programlama dilinde yazılan ve uygulamalarımızda kullanılan algoritmalar kullanıma açık olarak sunulmuştur.

\section{EK}

Algoritma 1: Gillespie algoritmas1

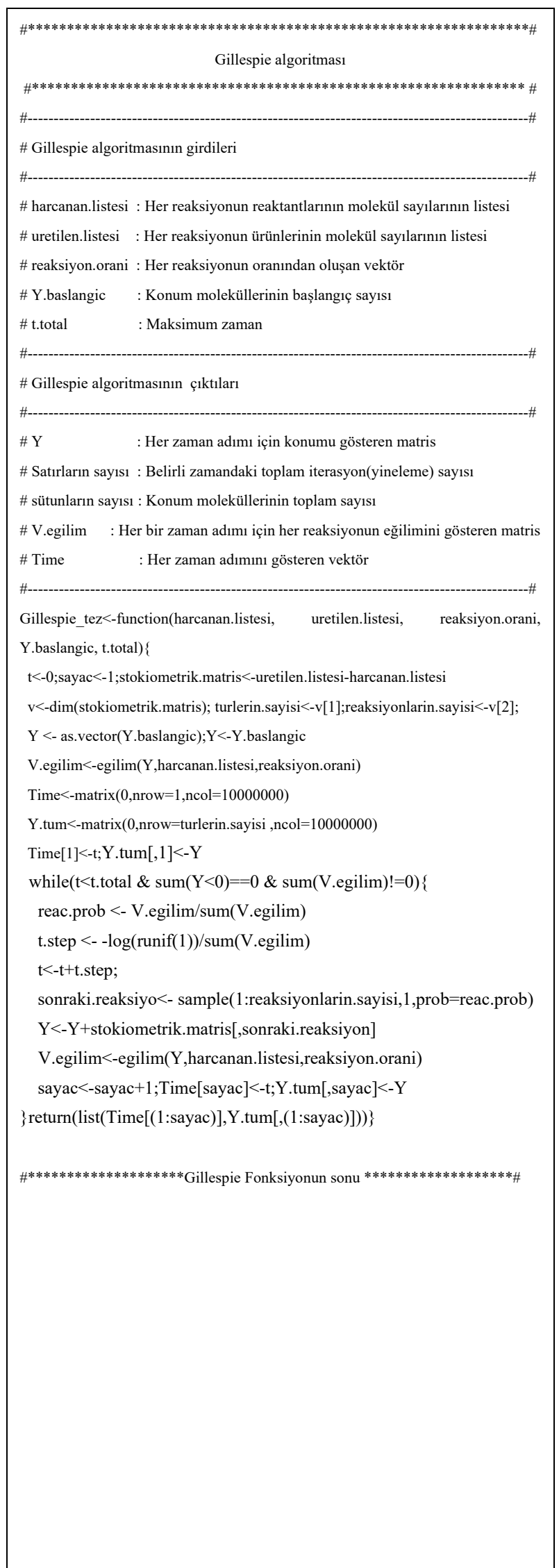




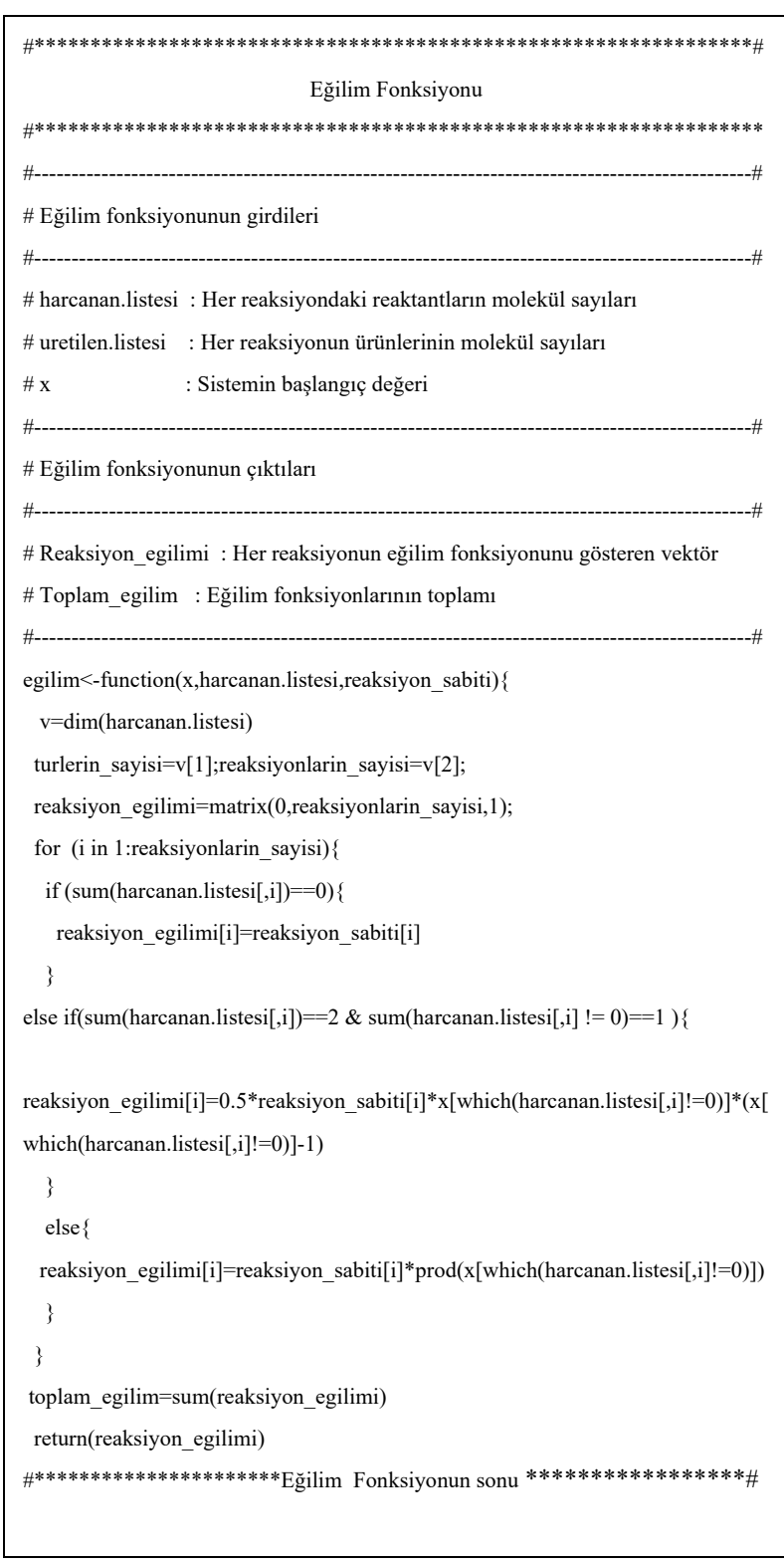

Algoritma 2: Doğum Ölüm ROD algoritması

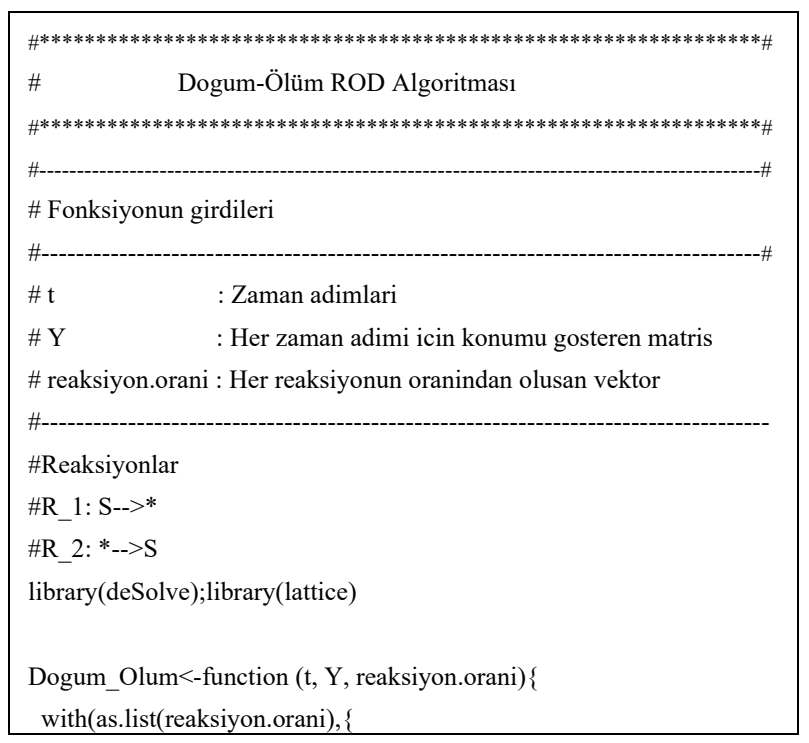

$\mathrm{dYdt}<$-reaksiyon.orani[2]-reaksiyon.orani[1]*Y return(list(c(dYdt)) )\}) \} \#************Dogum-Ölüm ROD Algoritmasının sonu $* * * * * * * * * * * * * \#$

Algoritma 3: Lotka-Volterra ROD algoritmas1

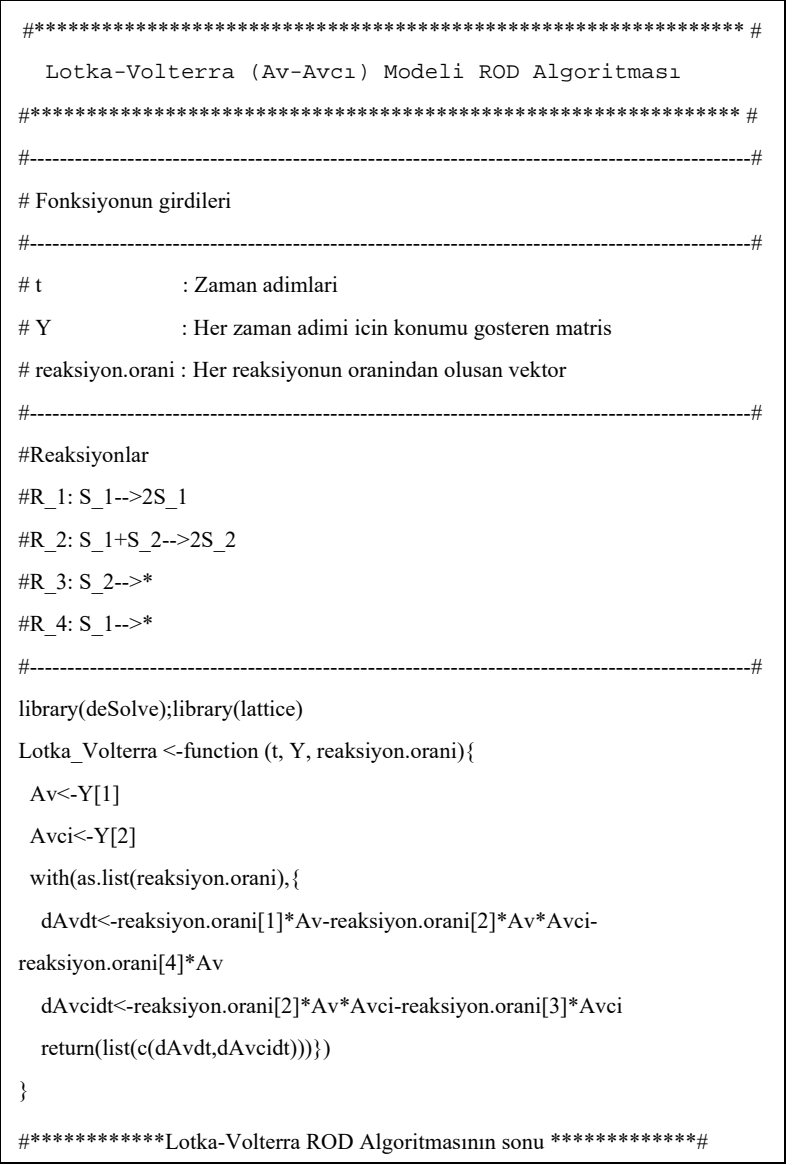

Algoritma 4: Glikoz ROD algoritması

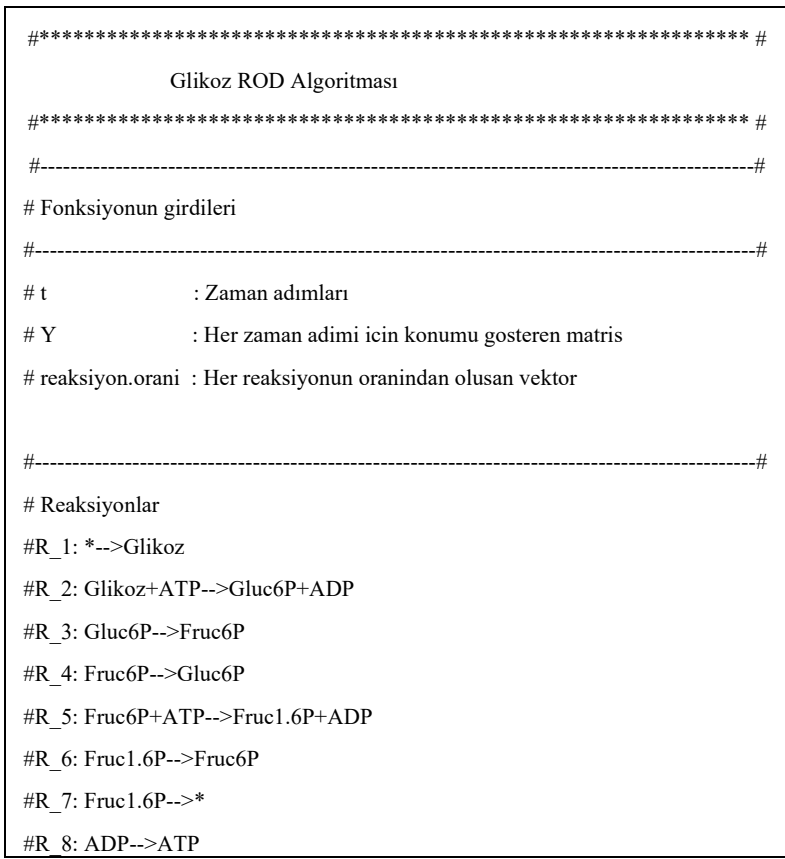




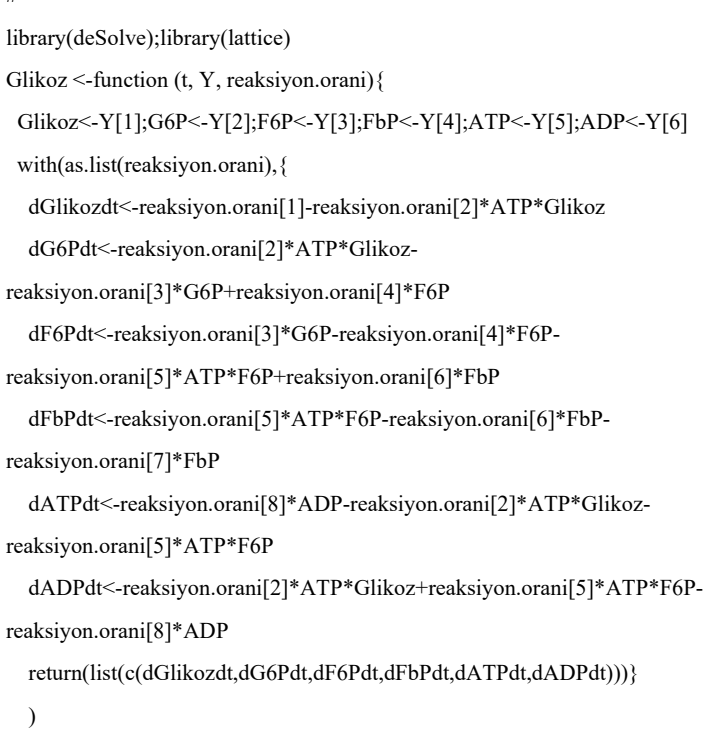

\section{Kaynaklar}

Arkin A, Ross J, McAdams HH (1998). Stochastic kinetic analysis of developmental pathway bifurcation in phage $\lambda$-infected Escherichia coli cells. Genetics 149(4): 1633-1648.

Altıntan D, Koeppl H (2020). Hybrid master equation for jump diffusion approximation of biomolecular reaction networks. BIT Numerical Mathematics 60(2): 261-294.

Cao Y, Li H, Petzold L (2004). Efficient formulation of the stochastic simulation algorithm for chemically reacting systems. Journal of Chemical Physics 121(9): 4059-4067.

Cao Y, Gillespie DT, Petzold LR (2005). The slow-scale stochastic simulation algorithm. $J$ Chem Phy 122: 014116.

Cao Y, Gillespie DT, Petzold LR (2006). Efficient step size selection for the tau-leaping simulation method. The Journal of Chemical Physics 124: 044109.

Crudu A, Debussche A, Radulescu (2009). Hybrid stochastic simplifications for multiscale gene networks. BMC Systems of Biology 3: 89.

Ganguly A, Altıntan D and Koeppl H (2015). Jump-diffusion approximation of stochastic reaction dynamics: Error bounds and algorithms. Multiscale Model Simul 13(4): 13901419.

Gibson MA, Bruck J (2000). Efficient exact stochastic simulation of chemical systems with many species and many channels. Journal of Physical Chemistry 104: 1876-1889.

Gillespie DT (1976). A general method for numerically simulating the stochastic time evolution of coupled chemical reactions. Journal of Computational Physics 22(4): 403434.

Gillespie DT (1977). Exact stochastic simulation of coupled chemical reactions. Journal of Physical Chemistry 81(25): 2340-2361. 
Gillespie DT (1992). A rigorous derivation of the chemical master equation. Physica $A$ 188(1-3): 404-425.

Gillespie DT (2001). Approximate accelerated stochastic simulation of chemically reacting systems. Journal of Chemical Physics 115(4): 1716-1733.

Gillespie DT (2007). Stochastic simulation of chemical kinetics. Annual Review of Physical Chemistry 58: 35-55.

Higham DJ (2008). Modeling and simulating chemical reactions. SIAM Review 347-368.

Jain MK (1984). Numerical solution of differential equations. New Delhi: Wiley Eastern.

Jahnke T, Altıntan D (2010). Efficient simulation of discrete stochastic reaction systems with a splitting method. BIT Numer Math 50: 797-822.

Jahnke T, Huisinga W (2007). Solving the chemical master equation for monomolecular reaction systems analytically. Journal of Mathematical Biology 54(1): 1-26.

Jilbert AR, Miller DS, Scougall CA, Turnbull H, Burrell CJ (1996). Kinetics of duck hepatitis b virus infection following low dose virus inoculation: One virus dna genome is infectious in neonatal ducks. Virology 226(2): 338-345.

Kampen NG (1981). Stochastic processes in physics and chemistry. Amsterdam; New York: North-Holland; New York: sole distributors for the USA and Canada, Elsevier NorthHolland.

Klipp E, Liebermeister W, Wierling C, Kowald A, Lehrach H, Herwig R (2009). Systems Biology: A Textbook. WILEY-VCH Verlag GmbH \& Co. KGaA.

Laise P, Di Patti F, Fanelli D, Masselli M, Arcangeli A (2011). Deterministic and stochastic aspects of vegf-a production and the cooperative behavior of tumoral cell colony. Journal of Theoretical Biology 272: 55-63.

Macnamara S, Burrage K, Sidje RB (2008). Multiscale modeling of chemical kinetics via the master equation. Multiscale Modeling and Simulation 6: 1146-1168.

McAdams HH, Arkin A (1997). Stochastic mechanisms in gene expression. Proc Natl Acad Sci 94: 814-819.

Murray JD (2003). Mathematical biology. New York: Springer.

Purutçuoğlu V, Wit E (2006). Exact and approximate stochastic simulations of the mapk pathway and comparisons of simulations results. Journal of Integrative Bioinformatics 3: $231-243$.

Rathinam M, Petzold LR, Cao Y, Gillespie DT (2003). Stiffness in stochastic chemically reacting systems: The implicit tau-leaping method. Journal of Chemical Physics 119(24): 12784-12794.

Roberts GCK (2013). Encyclopedia of Biophysics. EBSA, Springer.

Salis H, Kaznessis Y (2005). Accurate hybrid stochastic simulation of a system of coupled chemical or biochemical reactions. J Chem Phys 122: 054103.

Srivastava R, You L, Summers J, Yin J (2002). Stochastic vs. deterministic modeling of intracellular viral kinetics. Journal of Theoretical Biology 218(3): 309-321.

Steijaert M, Liekens A, Bosnacki D, Hilbers P, ten Eikelder H (2010). Single-variable reaction systems: Deterministic and stochastic models. Mathematical Biosciences 227: $105-116$. 
Steuer R (2004). Effects of stochasticity in models of the cell cycle: from quantized cycle times to noise-induced oscillations. Journal of Theoretical Biology 228(3): 293-301.

Ullah M, Schmidt H, Cho KH, Wolkenhauer O (2006). Deterministic modelling and stochastic simulation of biochemical pathways using matlab. Proceedings Systems Biology 153: 53-60.

Warmflash A, Dinner AR (2008). Signatures of combinatorial regulation in intrinsic biological noise. PNAS 105: 17262-17267.

Wilkinson DJ (2006). Stochastic modelling for systems biology. Chapman \& Hall/CRC mathematical and computational biology series. Boca Raton, FL: Taylor \& Francis. 